\title{
Microhabitat segregation of two coexisting tadpole species on Emei Mountain
}

\author{
Zijian Sun ${ }^{1,2}$, Chunlin ZhaO ${ }^{2,3}$, Dan Xu ${ }^{1,2}$, Wenbo Zhu ${ }^{2}$, Wenbo Fan ${ }^{2}$, Tian ZhaO ${ }^{1,2, *}$, Shengqi Su ${ }^{1, *}$ \\ ${ }^{1}$ College of Fisheries, Southwest University, Chongqing 400715, China \\ ${ }^{2}$ CAS Key Laboratory of Mountain Ecological Restoration and Bioresource Utilization \& Ecological Restoration Biodiversity Conserva- \\ tion Key Laboratory of Sichuan Province, Chengdu Institute of Biology, Chinese Academy of Sciences, Chengdu 610041, China \\ ${ }^{3}$ Key Laboratory of Bio-Resources and Eco-Environment of the Ministry of Education, College of Life Sciences, Sichuan University, \\ 610064, Chengdu, China \\ *Corresponding authors. E-mail: zhaotian@cib.ac.cn, sushengqi@swu.edu.cn
}

Submitted on: 2020, $19^{\text {th }}$ September; revised on: 2021, $3^{\text {rd }}$ March; accepted on: 2021, $8^{\text {rd }}$ March

Editor: Fabio M. Guarino

\begin{abstract}
Understanding mechanisms determining the coexistence between different species is one of the key issues in community ecology and biodiversity conservation. Microhabitat segregation is a way for species to coexist, which reflects the specific habitat selection of coexisting species in a finer spatial scale. Despite quantitative studies have been conducted to investigate the microhabitat segregation of coexisting species, this type of studies was not often performed on tadpoles. In this study, we assessed the habitat selection of two coexisting tadpoles (Quasipaa boulengeri and Leptobrachium boringii) in a stream on Emei Mountain, China. Our results demonstrated that L. boringii and Q. boulengeri tadpoles occupied different microhabitats. Specifically, Q. boulengeri tadpoles preferred deep, narrow, and weak acid stream segments with slow current velocity and low value of conductivity, while L. boringii tadpoles tended to occur in a wide, shallow water bodies with relatively higher $\mathrm{pH}$, conductivity, and current velocity. Overall, our study supported the Hutchinson's niche concept, showing that at least one dimension of niche differentiation (i.e., microhabitat) occurred between coexisting tadpole species.
\end{abstract}

Keywords. Microhabitat selection, species coexistence, niche differentiation, environmental variables.

\section{INTRODUCTION}

Understanding mechanisms determining the coexistence between different species is one of the key issues in community ecology and biodiversity conservation (Adler et al., 2010; Hanane, 2015). Previous studies indicated that coexisting species should occupy specific ecological niche (e.g., microhabitat niche, trophic niche; Grinnell, 1917) to evade competition based on the limiting similarity theory (Macarthur and Levins, 1967). As ecological niche is an $n$-dimensional ecological space satisfying all the essential conditions that support the organisms (Hutchinson, 1957), coexisting species exhibit at least one dimension of niche differentiation in the same ecosystem (Caceres and Machado, 2013; Hanane, 2015). This phenomenon can be referred to as niche partitioning involved in several facets, such as temporal or spatial distribution, as well as the trophic habits (Baker and Ross, 1981; de Andrade et al., 2014; Schoener, 1974). Therefore, Hutchinson's niche concept primarily focuses on habitats and resources utilization of sympatric species, as well as their environmental tolerances (Rosenfeld, 2002). Accordingly, the segregation of habitats can be considered as one of the important niche partitioning forms allowing the coexistence of species (Melo et al., 2013; Schoener, 1974; Wei et al., 2000). For instance, 
Guo et al. (2012) indicated that two species of goby fish (Rhinogobius giurinus and Rhinogobius cliffordpopei) were introduced into Lake Erhai, China in 1961. They eventually had to adapt to a different ecological niche in order to coexist in the ecosystem.

At a mesohabitat scale, habitat segregation is usually tested in physiognomically homogeneous units (Heggenes and Saltveit, 2007; Kano et al., 2013; Rezende et al., 2010). However, when focusing on species at a finer spatial scale, habitat segregation is usually assessed by measuring a set of environmental parameters (Rincon, 1999). This can reflect exact habitat utilization of coexisting species in the same ecosystem, particularly in the aquatic ecosystems (Jackson et al., 2001; Jorgensen, 2004; Leger et al., 1983; Leitao et al., 2015). For instance, two turtle species coexist in freshwater streams in Southwest of Iberian Peninsula due to their divergence in habitat selection. Specifically, the European pond turtle (Emys orbicularis) shows a preference for temporary, shallow, well vegetated, and sandy stream segment, while the Mediterranean pond turtle (Mauremys leprosa) tends to occupy deeper stream segment with more rocks (Segurado and Figueiredo, 2007). Similar situation is also observed in two coexisting fish species in Anizacate River. In this ecosystem, current velocity is the key factor that facilitates the coexistence of the stream catfish (Trichomycterus corduvense) and the eel catfish (Heptaterus mustelinus), who prefers the high-velocity and the low-velocity water flows, respectively (Hued and Bistoni, 2006). Despite quantitative studies have been conducted to investigate the microhabitat segregation of coexisting species in different ecosystems (e.g., invertebrates, Mammola et al., 2016; fish, Horinouchi, 2008; Kessler and Thorp, 1993; and amphibian adults, Ayala et al., 2018), empirical studies are still relatively rare in anuran tadpoles.

Tadpoles can exhibit plasticity in terms of functional traits (Jordani et al., 2019; Zhao et al., 2019), behavior (Freitas et al., 2019; Zhao et al., 2019), and metabolism (Freitas et al., 2019; Wang et al., 2019) in response to environmental change. In addition, tadpoles could influence the composition and abundance of plankton and periphyton, which has cascading effects on primary productivity in aquatic ecosystems (Alford and Wilbur, 1985; Seale, 1980; Strauss et al., 2010). More importantly, tadpoles are the larval stage of amphibian adults, which face multiple threats (e.g., habitat loss, climate change, and pollution, Alford, 2011). Therefore, identifying the microhabitat selection of coexisting tadpoles may bring important insights to tadpole biodiversity conservation, and suggest priorities for the improved management of mountain stream ecosystems.

In the present study, we evaluated the habitat selection of two coexisting tadpoles, Quasipaa boulengeri and
Leptobrachium boringii in a mountain stream. Specifically, we first compared the difference of variables of microhabitat occupied by L. boringii and Q. boulengeri tadpoles. We then explored the distribution pattern of the two tadpoles in the stream. Based on previous studies (e.g., Winston, 1995; Xu et al., 2020), we predict that the coexisting tadpoles of two different species occupy different microhabitat.

\section{MATERIAL AND METHODS}

\section{Study area and species description}

Field work was carried out in Heilongjiang stream, Qingyinge of Emei Mountain, Sichuan Province, China (Fig. 1). The vegetation of this area is mostly composed by evergreen broadleaved forest. The elevation of this region is about $680 \mathrm{~m}$ a.s.l., and the weather is characterized by subtropical monsoon climate. The mean annual temperature and the mean annual precipitation is about $17.29{ }^{\circ} \mathrm{C}$ and $1555.3 \mathrm{~mm}(\mathrm{Gu}$ and $\mathrm{Li}, 2008$; Ling, 2005). Several tadpoles belonging to different species were detected during our field work in this stream (e.g., Megophrys omeimontis, Megophrys minor, Odorrana graminea, Q. boulengeri, L. boringii, Leptobrachella oshanensis, and Odorrana schmackeri). The dominant species were L. boringii and Q. boulengeri, which occupied $90 \%$ of the proportion of the individuals. We focused on the divergences in habitat selection occurring between these two dominant species, as it would be more physiological than that showing how non-dominant species can coexist (Lyons et al., 2005; Barrett et al., 2008).

\section{Data collection}

Based on the distribution of target tadpoles and accessible for the sampling, one kilometer of the segment of the stream was selected as the transect. The transect was fixed and extended through a gorge, with strong variability in its physical variables due to the complex terrain and different vegetation cover rate. We divided this transect into three parts based on the blocking of rocks (i.e., approximate $200 \mathrm{~m}$ of the upstream transect, $450 \mathrm{~m}$ of the medium-stream transect, and $350 \mathrm{~m}$ of the downstream transect). Tadpole sampling was carried out after sunset (between 20:30 and 23:00) from 22 $2^{\text {nd }}$ to $27^{\text {th }}$ in August 2018. We searched at the both edges (about $1 \mathrm{~m}$ from the bank) of the stream where the tadpoles distributed, with one part of one side being sampled per night. Specifically, we divided each side of the transect into 1000 squares $(1 \times 1 \mathrm{~m})$, and two persons searched these plots of $1 \mathrm{~m}^{2}$ intensively from downstream to upstream using torch $(220 \mathrm{~lm})$. Once the target tadpoles were detected, the related square was recorded as one valid quadrat. After that, all the tadpoles located in the quadrat were collected by sweeping all potential microhabitats for tadpoles (i.e., water column and edge of rocks with and without vegetation) using hand nets (mesh size: $2 \mathrm{~mm}$ ). We assumed that tadpoles likely did not have chances to move from one side to the other 

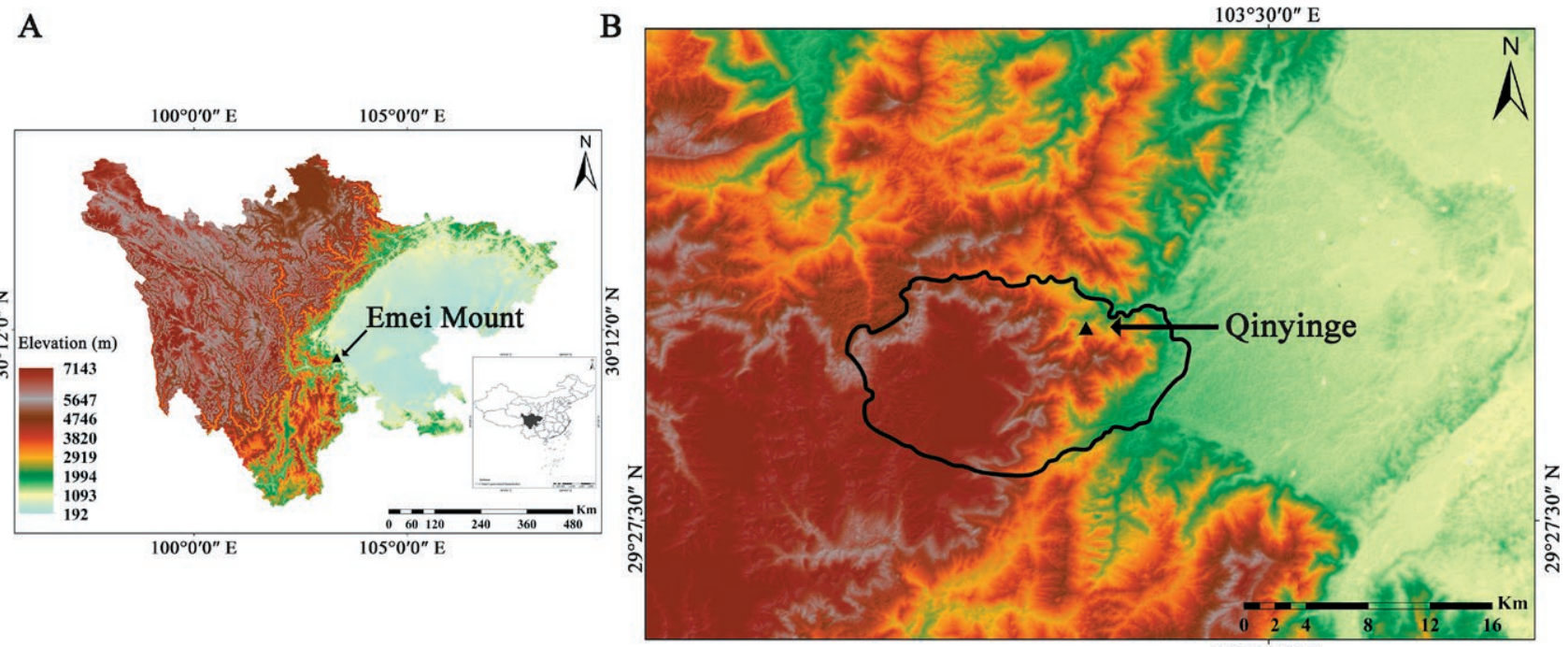

$103^{\circ} 30^{\prime} 0^{\prime \prime} \mathrm{E}$

Fig. 1. Geographical location of the study area. The solid line describes the range of Emei Mountain.

of the river, or to cross the rocks limiting the sections during the survey period. The two target tadpoles can be easily identified based on their external morphology. Specifically, there is a light " $Y$ " symbol at the back of $L$. boringii tadpole, while $Q$. boulengeri tadpole has flat head and back, thick caudal muscle, and I:4+4/1+1:II labial tooth row (Fei et al., 2012, Fig. S1). Collected tadpoles were kept in $500 \mathrm{ml}$ plastic bottles with freshwater from the stream separately. The stage of each tadpole was determined based on Gosner (1960).

In each quadrat where we found tadpoles, a set of eight environmental factors were measured. Details of the factors and the related measurement approaches are as follows: substrate type was divided into two groups (i.e., gravel and a mix of gravel and humus, associating with different food resources in the quadrats), water temperature was measured to the nearest $0.1^{\circ} \mathrm{C}$ by a thermometer (KTJ - TA318, China, Shenzhen), river width was measured to the nearest $0.1 \mathrm{~m}$ using a tape meter, the maximum depth of the quadrat was measured to the nearest $0.1 \mathrm{~cm}$ with a ruler, current velocity was measured to the nearness $0.1 \mathrm{~m} / \mathrm{s}$ using a portable current meter (LS1206B, China, Nanjing), $\mathrm{pH}$, conductivity (to the nearest $0.1 \mu \mathrm{S} / \mathrm{cm}$ ) and dissolved oxygen (to the nearest $0.1 \mathrm{mg} / \mathrm{l}$ ) were measured using a portable fluorescence photometer (Star A, 520M - 01A, Thermo Fisher Scientific, USA). During the measurements, the researcher remained outside the stream to do not affect the recorded parameters (Ferreira et al., 2015).

\section{Statistical analyses}

Shapiro-Wilk test was used to test the normality of the seven environmental variables of microhabitats. In order to compare the difference of variables of microhabitat occupied by L. boringii and Q. boulengeri tadpoles, we conducted Student's $t$ tests for variables which followed a normal distribution, or Mann-Whitney $U$ test for those were not normal distributed.
After that, we used detrended correspondence analysis (DCA) to explore the distribution pattern of the two tadpoles (linear model or single peak model). Considering the DCA axis lengths is less than 3 (i.e., the species distribution was fitted well with the linear model), we finally chose redundancy analyses (RDA) to quantify the environmental determinants of the distribution of the two target tadpoles. All statistical analyses were performed in $\mathrm{R}$ version 3.6.1 ( $\mathrm{R}$ development core team 2020) using the packages stats, spaa, and vegan.

\section{RESULTS}

In total, 27 quadrats were sampled and measured for environmental variables, in which 13 quadrats were occupied by L. boringii tadpoles, and 14 quadrats were occupied by $Q$. boulengeri tadpoles. These two tadpoles were not detected at the same time in each of the sampled quadrat. We overall captured 74 individuals of $L$. boringii from stage 24 to 37 and 193 individuals of Q. boulengeri from stage 25 to 43 .

Student's $t$ test indicated that there was no significant difference of dissolved oxygen $(t=-1.674, P=0.107)$ in the microhabitats that were occupied by $L$. boringii and $Q$. boulengeri tadpoles. Mann-Whitney $U$ tests revealed that $\mathrm{pH}$, conductivity, river width, water depth, and current velocity were significantly different $(P<0.05$; Fig. 2 ; substrate type cannot be tested as it was a categorical variable). Specifically, L. boringii tadpoles occupied quadrats that had higher values of $\mathrm{pH}$, conductivity, river width, and current velocity, but lower values of water depth. In contrast, $Q$. boulengeri tadpoles occupied quadrats that had lower values of $\mathrm{pH}$, conductivity, river width, 

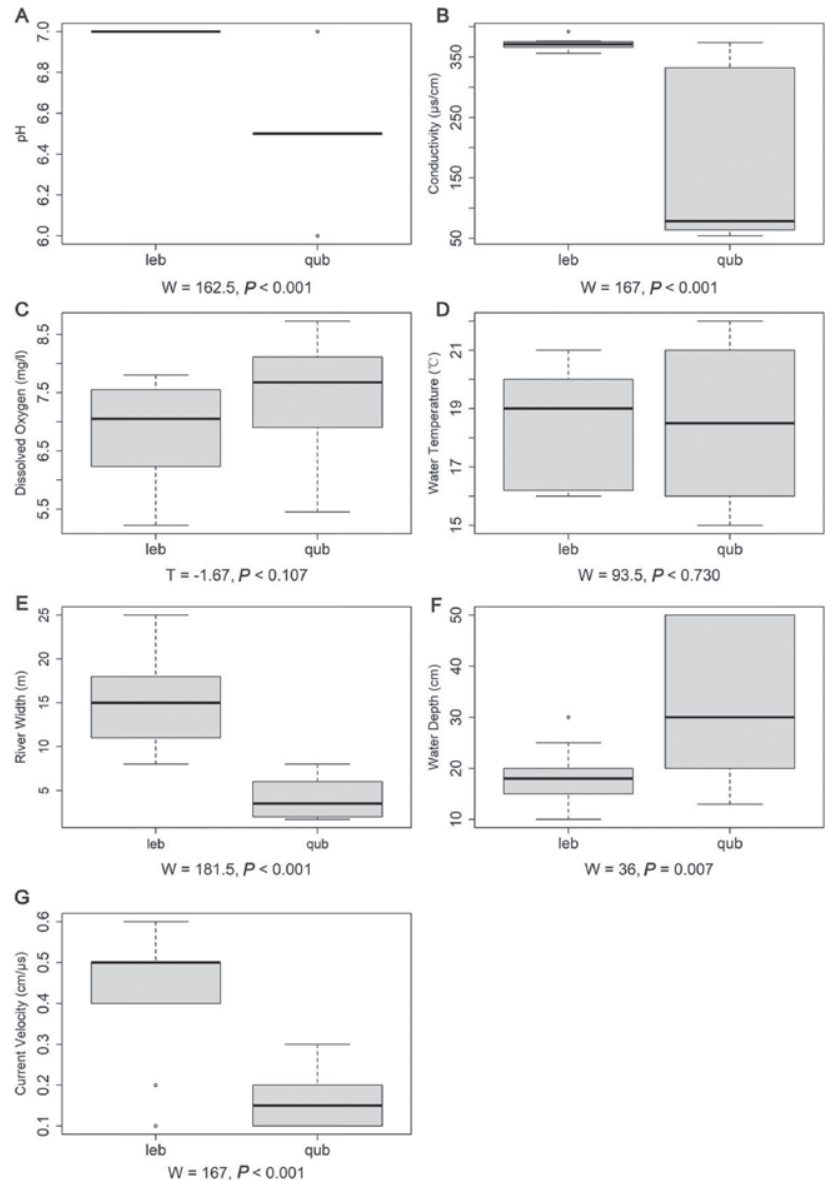

Fig. 2. Comparison of environmental variables of microhabitats between $L$. boringii tadpoles and Q. boulengeri tadpoles. "leb": $L$. boringii tadpoles, "qub": Q. boulengeri tadpoles.

and current velocity, but higher values of water depth. In addition, no significant difference existed in terms of water temperature values $(W=93.5 ; P>0.05)$.

The RDA model was significant when testing the environmental determinants of the distribution of $L$. boringii and $Q$. boulengeri tadpoles $(P=0.001)$. The first two axes accounted for $65.75 \%$ of the variation $(62.45 \%$ and $3.28 \%$, respectively). Our results revealed that five environmental factors including substrate type, river width, current velocity, $\mathrm{pH}$, and conductivity had highly significant effects on the distribution of $L$. boringii tadpoles and $Q$. boulengeri tadpoles $(P=0.001$, Table 1$)$, and the influence of water depth was significant $(P<0.05$, Table 1$)$. Obvious dissimilarity of the distribution of $L$. boringii and $Q$. boulengeri tadpoles could be observed in the RDA sequence diagram (Fig. 3). Specifically, most of the quadrats occupied by $L$. boringii tadpoles were distributed in the second and third quadrant densely, which were positively associated with current velocity, river width, $\mathrm{pH}$, conductivity, and sub-
Table 1. The influence of eight environmental factors tested by RDA analyses on the two tadpole species.

\begin{tabular}{lcccc}
\hline $\begin{array}{l}\text { Environmental } \\
\text { Variables }\end{array}$ & RDA1 & RDA2 & $\mathrm{r}^{2}$ & $P$ \\
\hline $\mathrm{pH}$ & -0.918 & 0.397 & 0.524 & $\mathbf{0 . 0 0 1}$ \\
Conductivity & -0.968 & 0.252 & 0.573 & $\mathbf{0 . 0 0 1}$ \\
Dissolved oxygen & 0.997 & 0.082 & 0.139 & 0.160 \\
Water temperature & -0.650 & 0.760 & 0.012 & 0.869 \\
River width & -0.847 & 0.531 & 0.596 & $\mathbf{0 . 0 0 1}$ \\
Water depth & 0.793 & -0.609 & 0.266 & $\mathbf{0 . 0 1 4}$ \\
Current velocity & -0.737 & 0.676 & 0.600 & $\mathbf{0 . 0 0 1}$ \\
Substrate type & -0.799 & 0.600 & 0.632 & $\mathbf{0 . 0 0 1}$ \\
\hline
\end{tabular}

Significant effects are indicated in bold.

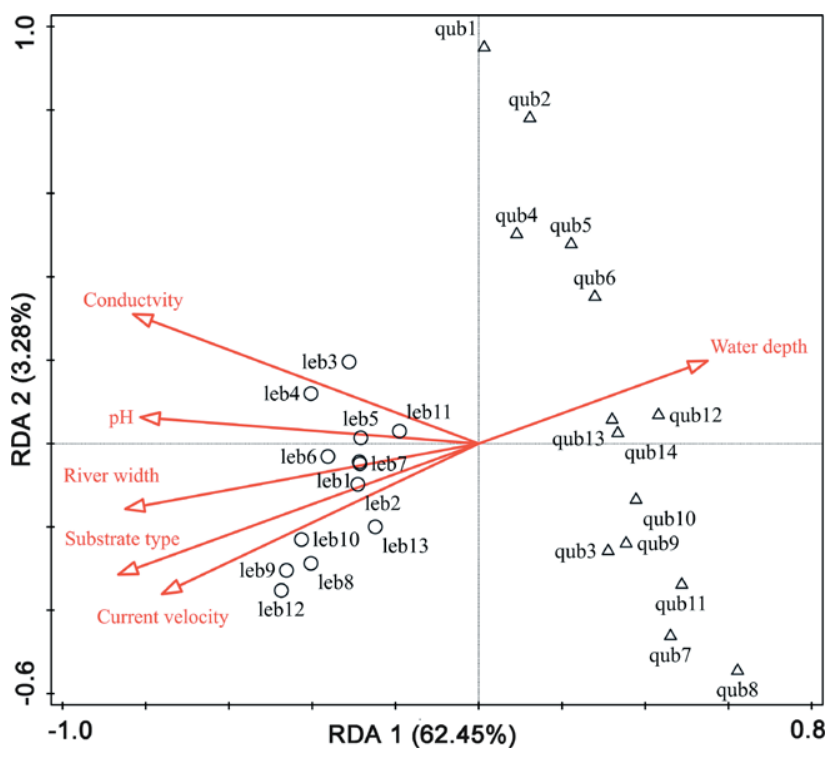

Fig. 3. Redundancy analyses of the relationships between environmental factors and the distributions of model tadpoles. The length of an environmental vector indicates the degree of correlations. Only significant variables are depicted $(P<0.05)$, "leb": L. boringii tadpoles, "qub": Q. boulengeri tadpoles.

strate type. However, they were negatively correlated with water depth. In contrast, most of the quadrats occupied by Q. boulengeri tadpoles exhibited opposite distribution pattern, which were positively correlated with water depth, and negatively associated with current velocity, river width, $\mathrm{pH}$, conductivity, and substrate type.

\section{DISCUSSION}

Discrepant preferences for microhabitat utilization on a small scale is often considered to be responsible for the 
coexistence of sympatric species (Dammhahn and Goodman, 2014; Dammhahn et al., 2013; Escoriza et al., 2018; Wei et al., 2000; Yang et al., 2019). Our results demonstrated that despite $Q$. boulengeri and $L$. boringii tadpoles co-occurred in the same stream, microhabitat segregation existed between them. Specifically, L. boringii tadpoles tended to occur in a wide, shallow water bodies with relatively higher $\mathrm{pH}$, conductivity, and current velocity, which was consistent with previous study (Wei et al., 2017). In contrast, $Q$. boulengeri tadpoles were apt to occupy deep, narrow stream segments with low $\mathrm{pH}$, conductivity and current velocity. Therefore, our results indicated that these two tadpoles occupied totally different microhabitat in this stream. Indeed, due to the poor movement ability, tadpoles' microhabitats are largely determined by the selection of breeding habitats by breeding adults (Biesterfeldt et al., 1993). Therefore, the occupation of the microhabitat of the two tadpole species were in accordance with previous observation showing that female Q. boulengeri spawned in puddles under the stream waterfall, while female $L$. boringii spawned at streams segments with more rocks and slow water flow (Fei et al., 2012).

It has been recognized that tadpole functional traits were correlated with their selection of microhabitats in water bodies (Fatorelli et al., 2015; Glos et al., 2017), as well as other factors (e.g., predatory occurrence and strategy, Mogali et al., 2020). Based on our previous study (Xu et al., 2020), these two tadpole species have distinct phenotypic functional traits, which also reflected their adaptation of different environment in the water bodies (Zhao et al., 2017). Specifically, Q. boulengeri tadpoles have flattened bodies and stubby tails, associating with their selection of deep and slow flowing water bodies. L. boringii tadpoles have long and muscular tails, which can be useful for them to swim when water velocity is high. These external functional traits reflect the food acquisition and locomotion of tadpoles, which are critical for them to obtain nutrients to survive, and to facilitate the movement in water bodies (Schoenfuss and Blob 2007). In the present study, substrate type was one of the main environmental factors determining the distribution of the two tadpoles, which probably related to their feeding preferences. That is, $Q$. boulengeri tadpoles tended to choose a substrate with gravels which can provide them adherent algae and benthos. In contrast, L. boringii tadpoles preferred a mixture of humus and gravels where organic detritus and invertebrates are more abundant. However, more work such as stable isotope analyses are needed to verify our inferences.

Overall, the present study evaluated the microhabitat segregation of two sympatric tadpole species in a mountain stream. Our observations supported Hutchinson's niche theory demonstrating that the existence of at least one dimension of niche differentiation between coexisting species. Therefore, specific microhabitat features should be incorporated into the conservation strategies for different species. Beyond our studies, future work could focus on the roles that coexisting species played in communities and ecosystems. Furthermore, as mountain streams are vulnerable to anthropogenic disturbance, how increasing fishing pressure on tadpoles from tourists may affect ecosystem functioning can be also tested.

\section{ACKNOWLEDGEMENTS}

We thank Janak R. Khatiwada, Xiaoyi Wang, Shengnan Yang, Xuecheng Guo, and Chunpeng Guo for their help during the field work. We also thank the Handling Editor Fabio M. Guarino and two anonymous Reviewers for their helpful suggestions that greatly improve this manuscript. This work is supported by National Natural Science Foundation of China (31700353), the Second Tibetan Plateau Scientific Expedition and Research Program (STEP), Grant No. 2019QZKK0501, and China Biodiversity Observation Networks (Sino BON). The Animal Care and Use Committee of Chengdu Institute of Biology, CAS provided full approval for this study (Number: CIB2011032201). Field work was approved by the Management O8ce of the Emei Mountain Management Committee (project number: EMS-201304006). The raw data of this study can be found in figshare (https://figshare. com/s/2130bf68ad78958e9492).

\section{SUPPLEMENTARY MATERIAL}

Supplementary material associated with this article can be found at <htttp://www.unipv.it/webshi/appendix> manuscript number 9758

\section{REFERENCES}

Adler, P.B., Ellner, S.P., Levine, J.M. (2010): Coexistence of perennial plants: an embarrassment of niches. Ecol. Lett. 13: 1019-1029.

Alford, R.A. (2011): Bleak future for amphibians. Nature 480: 461-462.

Alford, R.A., Wilbur, H.M. (1985): Priority effects in expermental pond communities-competition between Bufo and Rana. Ecology 66: 1097-1105.

Ayala, C., Ramos, A.G., Merlo, Á., Zambrano, L. (2018): Microhabitat selection of axolotls, Ambystoma mexica- 
num, in artificial and natural aquatic systems. Hydrobiologia 828: 11-20.

Baker, J.A., Ross, S.T. (1981): Spatial temporal resource utilization by southeastern cyprinids. Copeia 1981: 178-189.

Barrett, J.E., Virginia, R.A., Wall, D.H., Adams, B.J. (2008): Decline in a dominant invertebrate species contributes to altered carbon cycling in a low-diversity soil ecosystem. Global Change Biol. 14: 17341744.

Biesterfeldt, J.M., Petranka, J.W., Sherbondy, S. (1993): Prevalence of chemical interference competition in natural populations of wood frogs, Rana sylvatica. Copeia 1993: 688-695.

Caceres, N., Machado, A. (2013): Spatial, dietary and temporal niche dimensions in ecological segregation of two sympatric, congeneric marsupial species. Open J. Ecol. 6: 10-23.

Dammhahn, M., Goodman, S.M. (2014): Trophic niche differentiation and microhabitat utilization revealed by stable isotope analyses in a dry-forest bat assemblage at Ankarana, northern Madagascar. J. Tropic. Ecol. 30: 97-109.

Dammhahn, M., Soarimalala, V., Goodman, S.M. (2013): Trophic niche differentiation and microhabitat utilization in a species-rich montane forest small mammal community of Eastern Madagascar. Biotropica 45: 111118.

de Andrade, E.V.E., Palhas, I.J.L., de Moura, G.J.B. (2014): Diurnal habitat segregation by tadpoles in two temporary ponds in an Atlantic Rainforest remnant, Northeastern Brazil. Hydrobiologia 723: 181-194.

Escoriza, D., Pascual, G., Sanchez-Vialas, A. (2018): Habitat use in south-west European skinks (genus Chalcides). PeerJ 6: e4274.

Fatorelli, P., Pereira, E.G., Almeida-Gomes, M., Rocha, C.F.D. (2015): Population dynamics of Hylodes uai tadpoles (Anura, Hylodidae) in a tropical forest stream, southeastern Brazil. J. Herp. 49: 23-27.

Fei, L., Ye, C., Jiang, J. (2012): Colored atlas of Chinese amphibians and their distribution. ChengDu: Sichuan Science and Technology Press. (In Chinese with English Abstract).

Ferreira, R.L., Martins, V.M., Paixão, E.A., Silva, M.S. (2015): Spatial and temporal fluctuations of the abundance of Neotropical cave-dwelling moth Hypena sp. (Noctuidae, Lepidoptera) influenced by temperature and humidity. Subterr. Biol. 16: 47-60.

Freitas, J.S., Girotto, L., Goulart, B.V., Goncalves, Alho, L.D.O., Gebara, R.C., Montagner, C.C., Schiesari, L., Gaeta Espindola, E.L. (2019): Effects of 2,4-D-based herbicide (DMA (R) 806) on sensitivity, respiration rates, energy reserves and behavior of tadpoles. Ecotox. Environ. Safe. 182: 109446.

Glos J., Wolter, J., Struck, U., Rodel, M.O. (2017): Ecological shifts during larval development in two W,est African savanna frogs. J. Trop. Ecol.33: 50-59.

Gosner, K.L. (1960): A simplified table for staging anuran embryos and larvae with notes on identification. Herpetologists' League 16: 183-190.

Grinnell, J. (1917): Field tests of theories concerning distributional control. Am. Nat. 51: 115-128.

Gu, H.Y., Li, C.H. (2008): Preliminarily study. Acta Bot. Bor. Occ. Sin. 28: 2381-2387. (In Chinese with English Abstract).

Guo, Z.Q., Liu, J.S., Lek, S., Li, Z.J., Ye, S.W., Zhu, F.Y., Tang, J.F., Cucherousset, J. (2012): Habitat segregation between two congeneric and introduced goby species. Fundamental and Appl. Limn. 181: 241-251.

Hanane, S. (2015): Nest-niche differentiation in two sympatric Streptopelia species from a North African agricultural area: the role of human presence. Ecol. Res. 30: $573-580$.

Heggenes, J., Saltveit, S.J. (2007): Summer stream habitat partitioning by sympatric Arctic charr, Atlantic salmon and brown trout in two sub-arctic rivers. J. Fish Biol.71: 1069-1081.

Horinouchi, M. (2008): Patterns of food and microhabitat resource use by two benthic gobiid fishes. Environ. Biol. Fishes 82: 187-194.

Hued, A.C., Bistoni, M.D. (2006): Microhabitat use by two silurid species in the Anizacate River (central Argentina). Folia Zool. 55: 175-182.

Hutchinson, G.E. (1957): Population studies-Animal ecology and demography-Concluding Remarks. Cold Spring Harbor Symp. Quant. Biol. 22: 415-427.

Jackson, D.A., Peres-Neto, P.R., Olden, J.D. (2001): What controls who is where in freshwater fish communities - the roles of biotic, abiotic, and spatial factors. Can. J. Fish. Aquat. Sci. 58: 157-170.

Jordani, M.X., Mouquet, N., Casatti, L., Menin, M., Rossa-Feres, D.D., Albert, C.H. (2019): Intraspecific and interspecific trait variability in tadpole meta-communities from the Brazilian Atlantic rainforest. Ecol. Evol. 9: 4025-4037.

Jorgensen, E.E. (2004): Small mammal use of microhabitat reviewed. J. Mamm. 85: 531-539.

Kano, Y., Miyazaki, Y., Tomiyama, Y., Mitsuyuki, C., Nishida, S., Rashid, Z.A. (2013): Linking mesohabitat selection and ecological traits of a fish assemblage in a small tropical stream (Tinggi River, Pahang Basin) of the Malay Peninsula. Zool. Sci. 30: 178-184.

Kessler, R.K., Thorp, J.H. (1993): Microhabitat segregation of the threatened spotted darter (Etheostoma 
maculatum) and closely-related orangefin-darter (E. bellum). Can. J. Fish. Aquat. Sci. 50: 1084-1091.

Leger, D.W., Owings, D.H., Coss R.G. (1983): Behavioral ecology of time allocation in California groundsquirrels (Spermophilus beecheyi) microhabitat effects. J. Comp. Psyc. 97: 283-291.

Leitao, R.P., Sanchez-Botero, J.I., Kasper, D., Triverio-Cardoso, V., Araujo, C.M., Zuanon, J., Caramaschi, E.P. (2015): Microhabitat segregation and fine ecomorphological dissimilarity between two closely phylogenetically related grazer fishes in an Atlantic Forest stream, Brazil. Environ. Biol. Fishes 98: 2009-2019.

Ling, Z. (2005): Biodiversity monitoring and assessment report of Emei Mount. Chengdu, Sichuan Institute of Nature Science. (In Chinese with English Abstract)

Lyons, K.G., Brigha, C.A., Traut, B.H., Schwartz, M.W. (2005): Rare species and ecosystem functioning. Conserv. Biol. 19: 1019-1024.

Macarthur, R., Levins, R. (1967): The limiting similarity, convergence, and divergence of coexisting species. Am. Nat. 101: 377-385.

Mammola, S., Piano, E., Isaia, M. (2016): Step back! Niche dynamics in cave-dwelling predators. Acta Oecol. 75: 35-42.

Melo, G. L., Miotto, B., Peres, B., Caceres, N.C. (2013): Microhabitat of small mammals at ground, and understorey levels in a deciduous, southern Atlantic Forest. An. Acad. Bras. Cienc. 85: 727-736.

Mogali, S.M., Shanbhag B.A., Saidapur S.K. (2020): Adaptive significance of the transparent body in the tadpoles of ornamented pygmy frog, Microhyla ornata (Anura, Amphibia). Acta Herpetol. 15: 55-57.

$R$ development core team. (2020): R: a language and environment for statistical computing. Retrieved from http://www.R-project.org/. [Accessed 15 Sep 2020].

Rezende, C.F., Moraes, M., Manna, L.R., Leitao, R.P., Caramaschi, E.P., Mazzoni, R. (2010): Mesohabitat indicator species in a coastal stream of the Atlantic rainforest, Rio de Janeiro-Brazil. Rev. Biol. Trop. 58: 1479-1487.

Rincon, P. (1999): Microhabitat use by fishes in a small streams: methods and perspectives. Oecol. Aust. 6: 23-90.

Rosenfeld, J.S. (2002): Functional redundancy in ecology and conservation. Oikos 98: 156-162.

Schoener, T.W. (1974): Resource partitioning in ecological communities. Science 185: 27-39.

Seale, D.B. (1980): Influence of amphibian larvae on primamary production, nutrient flux, and competition in a pond ecosystem. Ecol. 61: 1531-1550.

Segurado, P., Figueiredo, D. (2007): Coexistence of two freshwater turtle species along a Mediterranean stream: the role of spatial and temporal heterogeneity. Acta Oecol. 32: 134-144.

Strauss A., Reeve E., Randrianiaina R.-D., Vences M., Glos J. (2010): The world's richest tadpole communities show functional redundancy and low functional diversity: ecological data on Madagascar's streamdwelling amphibian larvae. BMC ecology 10: 12.

Wang, X., Chang, L., Zhao, T., Liu, L., Zhang, M., Li, C., Xie, F., Jiang, J., Zhu, W. (2019): Metabolic switch in energy metabolism mediates the sublethal effects induced by glyphosate-based herbicide on tadpoles of a farmland frog Microhyla fissipes. Ecotoxicol. Environ. Saf. 186: 1-11.

Wei, F. W., Feng,, Z. J., Wang Z. W., Hu, J. C. (2000): Habitat use and separation between the giant panda and the red panda. J. Mamm. 81: 448-455. (In Chinese with English Abstract)

Wei, G., Zhang, W. Y., Guo, P. (2017): Amphibians in Fanjingshan Mount. Guizhou, Guizhou Science and Technology Publishing House Co., Ltd. (In Chinese)

Winston, M. R. (1995): Co-occurrence of morphologically similar species of stream fishes. Am. Nat. 145: 527-545.

Xu, D., Wu, X. Q., Zhao, C. L., Zhu, W. B., Zhao, T., Su, S. Q. (2020): Functional approach reveals niche differentiation between two coexisting tadpoles: Leptobrachium boringii and Quasipaa boulengeri. Acta Ecol. Sin. 40: 43-50 (In Chinese with English Abstract).

Yang, S. N., Jiang, J. P., Luo, Z. H., Yang, X., Wang, X. Y., Liao, W. B., Hu, J. H. (2019): Microhabitat segregation of parapatric frogs in the Qinling Mountains. Asian Herp. Res. 10: 48-55.

Zhao, T., Li, C., Wang, X., Xie, F., Jiang, J. (2017): Unraveling the relative contribution of inter- and intrapopulation functional variability in wild populations of a tadpole species. Ecol. Evol. 7: 4726-4734.

Zhao, T., Wang, X. Y., Wang, X. G., Wang, S. S., Chen, Y. H., Jiang, J. P. (2019): Effects of urea on behavior and functional traits of Asiatic toad (Bufo gargarizans) tadpoles. Aquatic Ecol. 53: 9-19. 